\title{
Silver Nanoparticle-Doped Titanium Oxide Thin Films for Intermediate Layers in Organic Tandem Solar Cell
}

\author{
Wanyi Nie, Robert C. Coffin, and David L. Carroll \\ Center for Nanotechnology and Molecular Materials, Department of Physics, Wake Forest University, Winston-Salem, \\ NC 27109, USA \\ Correspondence should be addressed to David L. Carroll; carroldl@wfu.edu
}

Received 25 September 2012; Accepted 31 December 2012

Academic Editor: K. N. Narayanan Unni

Copyright (C) 2013 Wanyi Nie et al. This is an open access article distributed under the Creative Commons Attribution License, which permits unrestricted use, distribution, and reproduction in any medium, provided the original work is properly cited.

In this work we investigate the Ag nanoparticle doping of TiOx used as an intermediate layer between subcells of a tandem organic photovoltaic. We use a model polymer cell structure of P3HT:TiOx:PEDOT:P3HT to observe charge-trapping effects as a function of nanoparticle content in the TiOx, as determined by the shape of the dark and illuminated current voltage curves of the devices. There is a direct correlation between the amount of Ag nanoparticles in the TiOx, and interfacial charge buildup, and charge trapping being completely mitigated at around $0.2 \%$ mol. This suggests that such doping schemes might provide a simple approach to the creation and use of TiOx layers for tandem cells.

\section{Introduction}

Polymer-based organic solar cells in single-layer bulk heterojunction have now demonstrated power conversion efficiencies (PCEs) of between 7\%-9\% [1-3]. These efforts have improved the solar cell performance by modifying the chemical structure $[4,5]$ of the polymers or of the bulk heterojunction acceptor [6] which has yielded improvements to the filling factor (FF) through better packing and the short circuit current density (Jsc) through smaller bandgaps. However, the PCE of such cells remains limited by the open circuit voltage (Voc) [7], which arises from the difference between donor highest occupied molecular orbital (HOMO) level and acceptor lowest unoccupied molecular orbital (LUMO) level $[8,9]$. Given the optical absorption bandgap and the need to set the acceptor levels sufficiently below the polymer's LUMO for efficient exciton separation, increasing the Voc in a singlelayer bulk heterojunction device can be challenging.

A popular approach to increasing the Voc in such circumstances is the use of a series-connected solar cell configuration: a "tandem solar cell," in which two or three polymer solar cells with different optical bandgaps, matched across the solar spectrum, are stacked together [10]. Typically, in tandem devices, there is an interconnection layer (ICL) between the subcells that serve to allow current flow through the device. This interlayer has to be sufficiently conductive and transparent for charge and light to pass unimpeded. This further requires the Fermi level to be in a specific range depending on the LUMO of the front-cell acceptor and HOMO of the back-cell donor for the charge collection and voltage add up. Finally, since this ICL can allow for the recombination of electrons generated by the front cell and the holes from the back cell (for noninverted subcells), mobility must be high, meaning no charge trapping. Examples of interlayers successfully demonstrated to meet some of these requirements and connect the subcells are ultrathin metal films of silver or gold [11, 12]; vacuum deposited metal oxide (i.e., indium tin oxide (ITO), molybdenum trioxide $\left(\mathrm{MoO}_{3}\right)$ $[13,14]$ or solution processed metal oxides (such as Titanium Oxide and Zinc Oxide)) [15].

Most studies insert $\mathrm{TiOx}$ or $\mathrm{ZnOx}$ as an electron transport layer (ETL), together with poly(3,4-ethylenedioxythiophene) poly(styrenesulfonate) (PEDOT:PSS) between the front cell and back cell, that provides a region for holes generated by the front cell and electrons transported from the back cell. But these suffer from insufficient electron mobility and result in a space charge trapping that leads to a fill factor reduction in tandem devices using $\mathrm{ZnO}[16]$ and $\mathrm{TiOx}[17,18]$ as ETL. However, when irradiated with UV light, such as from a solar simulator with the UV filter removed, mobility 
is restored as a charge balance in both $\mathrm{ZnO}$ and $\mathrm{TiOx}$ cases [17-19]. This effect has been interpreted as UV-stimulated detrapping of charge traps between the conductive PEDOT, which can be treated as metallic hole conductor, and then type semiconductive metal oxide ( $\mathrm{TiOx}$ or $\mathrm{ZnOx})[16,17]$. We note that an opposite phenomenon has been observed in Pandey et al's work [20], and this could be attributed to the Fermi level variation owing to the surface states and impurities for nanoporous $\mathrm{TiO}_{2}$ films mentioned in the literature, which is different from our method.

In this study, we present an alternative method for electron activation. Following the work of photosensors [21], we employ the use of silver nanoparticles to dope the metal oxide. Focusing on solution-processed $\mathrm{TiOx}$, we show that improvements in the conductivity and charge carrier mobility can be similar to those in the UV-activated case $[21,22]$. Similar effect has been observed by Liu and Nunzi [23] by depositing $1 \mathrm{~nm}$ gold nanoparticles between two subcells in an inverted tandem cell configuration for space charge removal, which confirms our observation. This is demonstrated in a model P3HT system; however, the results can be applied to polymer devices with different bandgaps in the subcells, allowing for more efficient spectral splitting and charge collection generally.

\section{Experiment}

The detailed recipe for the preparation of TiOx sol-gel solutions has been reported elsewhere in the literature [24, 25]. Briefly, the sol gel is prepared from the hydrolysis of titanium (IV) isopropoxide (Aldrich, 99.9\%) by water with the present of nitric acid $\left(\mathrm{HNO}_{3}\right)$ [26] as catalyst and acetylacetone as chelating agent [18] under vigorous stirring. The obtained clear gel is heated in an oven at $60^{\circ} \mathrm{C}$ for 24 hours and aged for three days. Silver doping was achieved by subsequently dissolving silver nitrate in distilled water and added in TiOx solution ( 0.2 w.t. $\%$ in ethanol) by $0.1 \mathrm{~mol} \%, 0.2 \mathrm{~mol} \%$, $0.4 \mathrm{~mol} \%$, and $1.0 \mathrm{~mol} \%$. After white light illumination during stirring for 24 hours, silver nanoparticles will be formed in the solution.

Prepatterned indium tin oxide (ITO) coated glass substrates (Delta Technologies) were cleaned by detergent and ozone treated for $30 \mathrm{~min}$ after drying in a vacuum oven. A blend solution of regioregular poly(3-hexylthiophene) (P3HT) (Reike Metal) and phenyl-C61-butyric acid methyl ester (PCBM) (as received from NANO.C) at a ratio of 1: 0.8 in chlorobenzene was spun cast onto the poly $(3,4$-ethylenedioxythiophene) poly(styrenesulfonate) (PEDOT:PSS 4083), a $40 \mathrm{~nm}$ hole transporting layer formed by spin coating at $4000 \mathrm{rpm}$ for 45 seconds, coated substrates at $1500 \mathrm{rpm}$ for $30 \mathrm{sec}$. A thin layer of TiOx with silver doping ratio of $0 \mathrm{~mol} \%$ (D00), $0.1 \mathrm{~mol} \%$ (D01), $0.2 \mathrm{~mol} \%$ (D02), $0.4 \mathrm{~mol} \%$ (D04), and $1.0 \mathrm{~mol} \%$ (D10) was spin coated at $1000 \mathrm{rpm}$ on top of active layer. After the second PEDOT:PSS (PH500) film ( 100 nm) was formed and baked at $130^{\circ} \mathrm{C}$ for $10 \mathrm{~min}$, the back cell from the same P3HT:PCBM blend solution was spun casted at $1500 \mathrm{rpm}$ to keep the thickness the same as the front active film. After the film was dried, the devices were transferred to a vacuum chamber $\left(<1.0 * 10^{-6}\right.$ torr $)$ for $\mathrm{LiF}(0.3 \mathrm{~nm})$ and aluminum $(100 \mathrm{~nm})$ back contact deposition.

The solar cells were tested using a standard AM $1.5 \mathrm{~g}$ solar simulator at $100 \mathrm{~mW} / \mathrm{cm}^{2}$. The active area of the devices is carefully masked while testing and determined to be between $0.08 \sim 0.12 \mathrm{~cm}^{2}$. The current-voltage characteristics are collected by Keithley 230.

\section{Result and Discussion}

The formed $\mathrm{TiOx}$ particles in thin film by spun casting this solution on glass substrate can be seen in the Field Emission Scanning Electron Microscopy (FESEM) image in Figure 1. The particles are closely packed in the film with an average size of $30 \mathrm{~nm}$, which is comparable to literature stated [27, 28]. The TEM images in Figure 1(b) confirm a uniform porous $\mathrm{TiOx}$ matrix formed by this sol-gel method. By adding silver nitrite water solution in the $\mathrm{TiOx}$ ethanol solution and illuminated with white light for 24 hours, the silver nanoparticles are decomposed from silver nitrite and distributed uniformly in the $\mathrm{TiOx}$ matrix with a size of $5 \sim 10 \mathrm{~nm}$. This can be observed as black spots by TEM in Figure 1(c) comparing with the nondoped film.

With a work function of $4.27 \mathrm{eV} \pm 0.05 \mathrm{eV}$, the solgel-derived amorphous titanium oxide ( $\mathrm{TiOx}$ ) should act as an electron-transporting layer (ETL) [29] in the solar cell. To test the $\mathrm{TiOx}$ performance as ETL in single-junction device, solar cells in the structure of ITO/PEDOT:PSS(4083)/P3HT:PCBM/TiOx/Al were fabricated and characterized by the IV curve under one sun illumination as shown in Figure 2(a). It is clear that the device with nondoped TiOx film exhibits an "s-shaped" JV curve near Voc. This indicates that space charge has been built up between cathode and active layer due to the insufficient charge carrier mobility, which corresponds to a low filling factor of 0.405 [19]. Once a small amount of silver nanoparticles $(0.1 \mathrm{~mol} \%)$ are added, the trapped charge, as indicated by the JV curve shape, has been removed, and a higher fill factor can be achieved $(\mathrm{FF}=0.446)$. This was confirmed by performing a JV measurement (Figure 2(b)) on a diode fabricated by inserting TiOx layer between ITO and aluminum. Further increasing the doping level raises the fill factor to 0.605 at $0.2 \mathrm{~mol} \%$.

Since the electron tends to go to a higher-energy level from acceptor LUMO $(-3.7 \mathrm{eV})$ to cathode Fermi level $(-4.06 \mathrm{eV})$, the electron transporting layer work function needs to be high enough to maintain the Voc. The nondoped TiOx layer work function was measured to be $4.27 \pm 0.05 \mathrm{eV}$, which is similar to other studies [17]. This suggests the silver nanoparticles (work function $=4.5 \sim 4.7 \mathrm{eV}$ ) increase the work function as expected. The Voc $(\sim 0.66 \mathrm{~V} \pm 0.02)$ was relatively constant at low levels of doping between $0.1 \mathrm{~mol} \%$ and $0.4 \mathrm{~mol} \%$. However, it starts to drop by $10 \%$ at a higher doping $(1.0 \mathrm{~mol} \%)$ due to the work function increase up to $4.79 \mathrm{eV} \pm 0.03 \mathrm{eV}$ as measured.

The ICL in tandem cell serves as a charge recombination layer for electron transported from the acceptor of front cell and the hole generated by the back cell and has to be both transparent to visible radiation and electrically compatible 


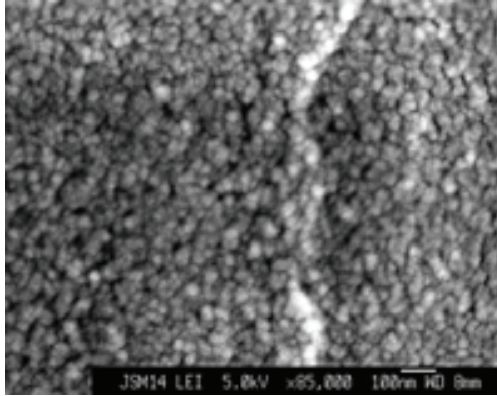

(a)

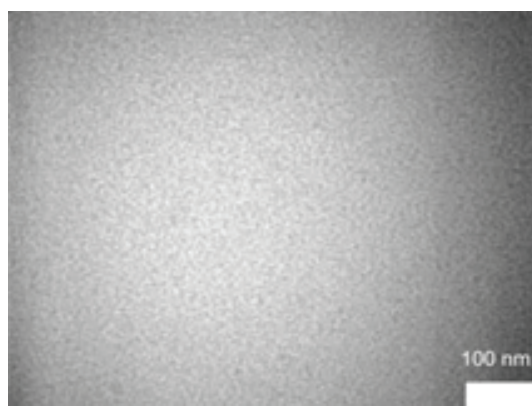

(b)

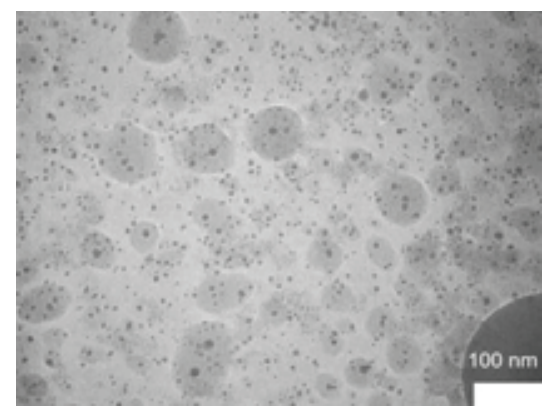

(c)

Figure 1: (a) FE-SEM image for TiOx thin film spun casted on glass substrate and TEM images on TiOx thin film (b) with 0.4 mol\% silver nanoparticles and (c) without silver.

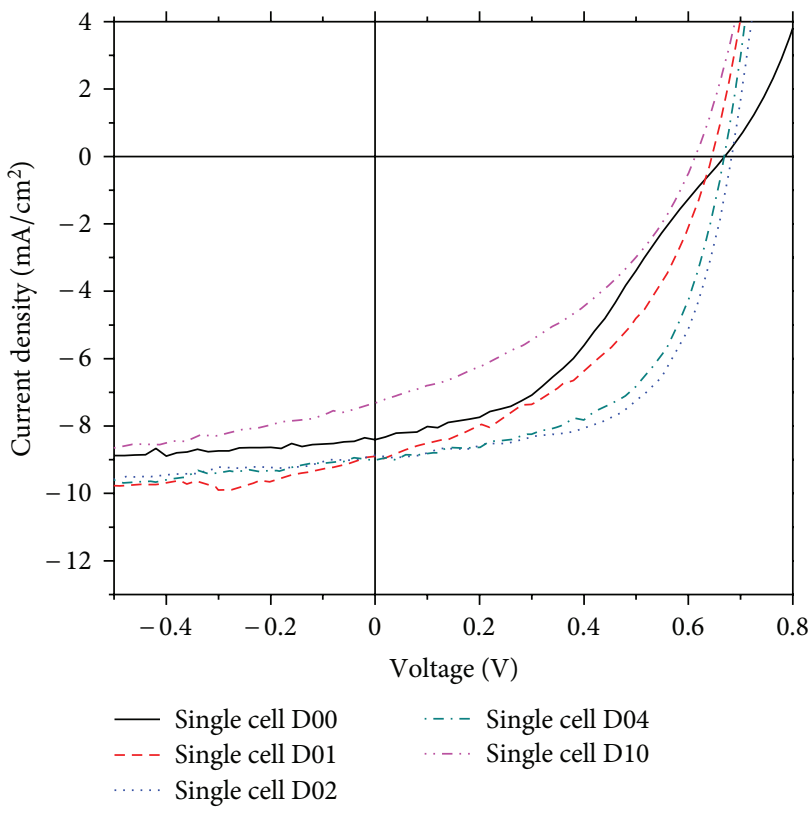

(a)

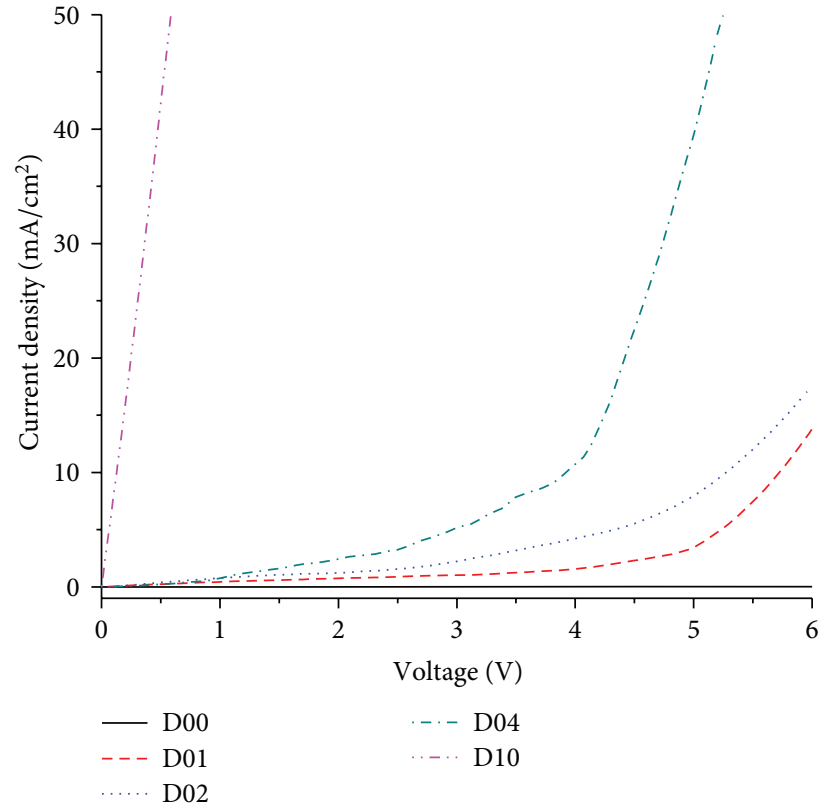

(b)

Figure 2: (a) Single junction device performance under standard illumination with TiOx as electron transport layer and (b) electron mobility in TiOx thin film diode without doping (black square) and doped by silver nanoparticles.

with the two subcells [30]. In our study, the combination of TiOx (with and without doping) as ETL and PEDOT:PSS as hole transport layer (HTL) was used as ICL between two identical absorbing layers composed of P3HT:PCBM at a ratio of 0.8 . The thickness of the active layer of front cell has been kept the same as that in the back cell for all devices. The transparency of ETL thin films (with and without silver nanoparticles) was tested and is shown in Figure 3(a). It shows the transmission of $98 \%$ over the range of $300 \mathrm{~nm}$ to $1000 \mathrm{~nm}$. The doped TiOx has a thickness of $20 \mathrm{~nm}$ in this study. In terms of the electrical behavior, however, the PEDOT has a work function of $5.2 \mathrm{eV}$, which induces a Schottky barrier at the interface between PEDOT and TiOx, leading to an insufficient charge recombination and voltage loss. The diodes in Figure 3(b) have a structure of ITO/PEDOT:PSS (PH500)/TiOx(silver)/Al, and the undoped diode shows a Schottky curve while the doped diodes show ohmic contacts, which aids in charge transfer. From this we conclude that the doped layers should allow for light and charge transfer within the tandem structure.

The tandem devices were fabricated by inserting the above intermediate layers between two identical P3HT:PCBM bulk-heterojunction subcells, and the back contact was the combination of LiF and aluminum. As shown in Figure 4, the IV curve for the device fabricated by nondoped TiOx/PEDOT:PSS as interlayer has a " $\mathrm{S}$ " shaped curve under standard illumination near Voc, which is the Schottky barrier caused by the interface between TiOx and PEDOT:PSS, resulting in a low filling factor of 0.373 and $\mathrm{Voc} \sim 1.135 \mathrm{~V}$ with a potential loss. With a small amount of silver nanoparticles in $\mathrm{TiOx}(0.1 \mathrm{~mol} \%)$, the "S" shape is partly corrected. Increasing the silver further to 


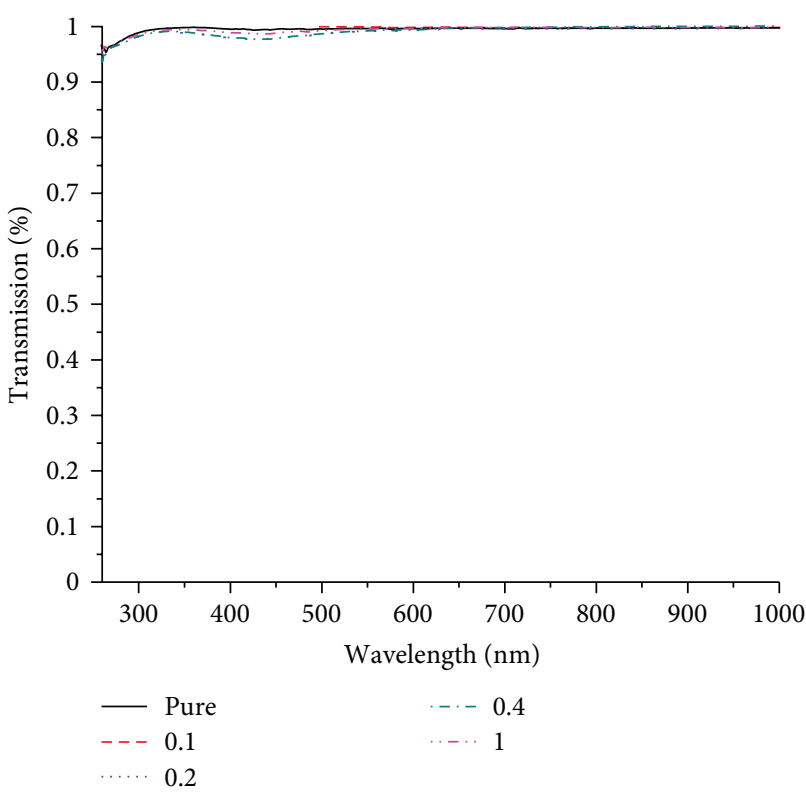

(a)

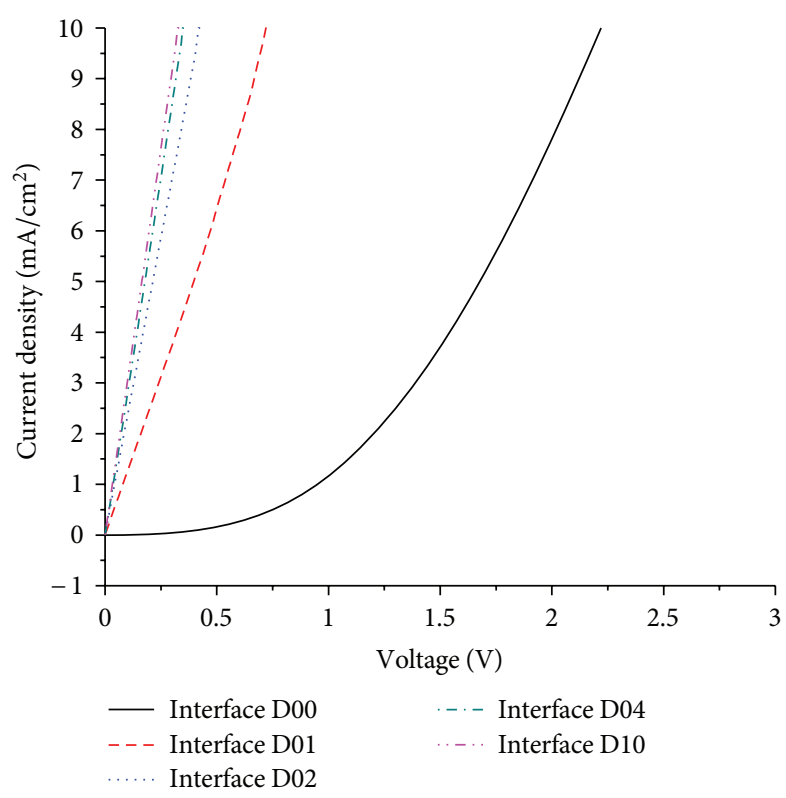

(b)

Figure 3: (a) IV characteristic of devices with structure of ITO/PEDOT:PSS/TiOx/Al diode and (b) transmission with TiOx thin film at changing amount of silver dopant from $0.1 \mathrm{~mol} \%$ to $1 \mathrm{~mol} \%$.

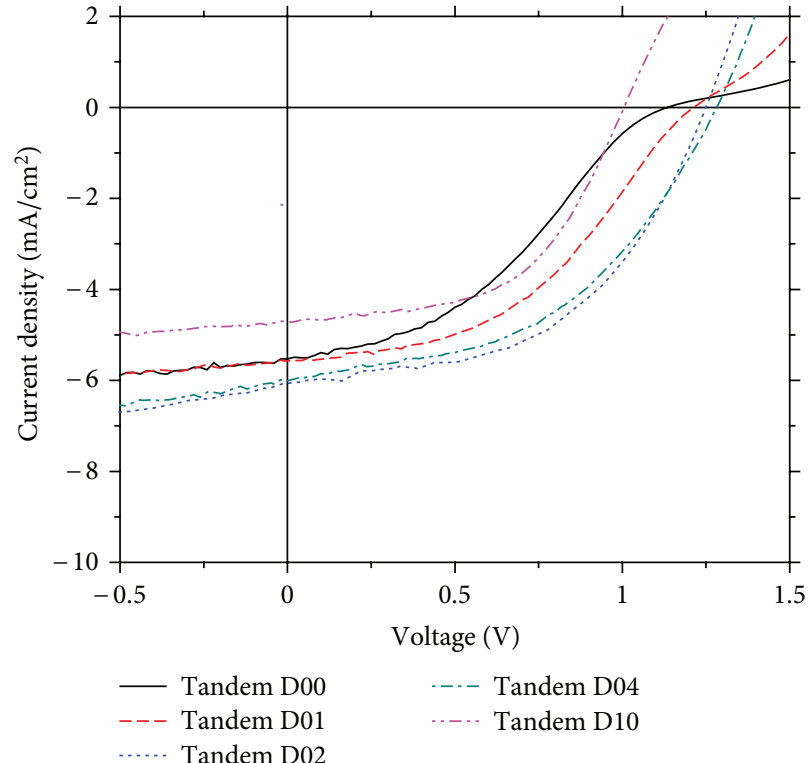

(a)

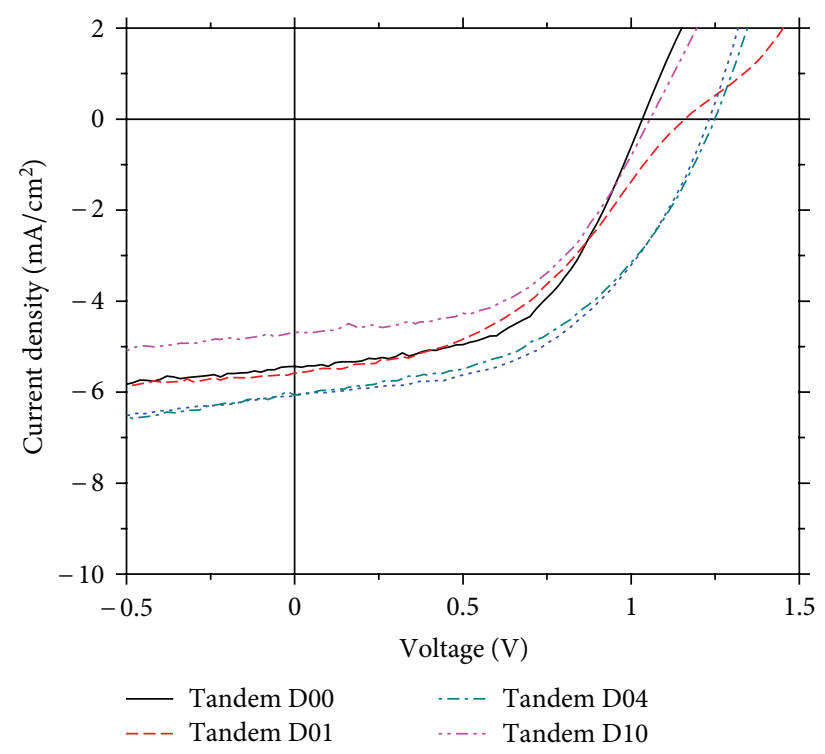

(b)

FIGURE 4: IV curves of single-junction device and tandem devices with doped and undoped TiOx interlayer under standard AM 1.5 solar simulator illumination when (a) UV filter not removed and (b) UV filter removed.

$0.2 \sim 0.4 \mathrm{~mol} \%$, the Voc increased up to $1.25 \mathrm{~V} \sim 1.28 \mathrm{~V}$, which is roughly the sum over two single junction devices $(0.66 \mathrm{~V})$. The fill factor has also increased nearly 50\% compared to nondoped device, resulting in a PCE 3.63\% \pm 0.11 . For a higher doping at $1.0 \mathrm{~mol} \%$, the device shows a slightly higher fill factor of 0.537 but a reduced Voc of $1.01 \mathrm{~V}$ which limits the PCE to around $2.5 \%$.
By removing the UV filter in the solar simulator, and illuminating the undoped films, a similar effect was observed as in literature $[18,19]$. The UV light activated the TiOx layer and removed the "S" curve near Voc, which increases FF from 0.314 up to 0.541 . However, no significant change in the IV curve occurred by UV illumination for the doped $\mathrm{TiOx}$ layer devices. 


\section{Conclusion}

This work investigated the use of $\mathrm{Ag}$ nanoparticles as a dopant for $\mathrm{TiOx}$ films used in organic photovoltaics. Singlejunction devices were fabricated first, to test the TiOx performance as an electron transport layer. At the $0.2 \mathrm{~mol} \%$ silver doping level of the $\mathrm{TiOx}$, the single-layer devices exhibited improved rectification in the IV curve compared to the devices with nondoped film. In the model, tandem P3HT photovoltaic, where the $\mathrm{TiOx}$ is used as an interlayer for transfer, the nanoparticle dopant increased the charge mobility and removed the Schottky barrier between the second PEDOT:PSS layer. The tandem solar cells using doped TiOx film also exhibited the expected addition of the open-circuit voltage $(1.28 \mathrm{~V})$ for low doping levels. However, for higher Ag doping the open circuit voltage begins to drop indicating misalignment of the energy levels of the system. This work is applicable to tandem devices that utilize multiple bandgaps in the subcells and suggests that nanoparticle doping schemes may play an important role in band alignment and carrier mobility as well as light scattering.

\section{References}

[1] Y. Liang, Z. Xu, J. Xia et al., "For the bright future-bulk heterojunction polymer solar cells with power conversion efficiency of 7.4\%," Advanced Materials, vol. 22, no. 20, pp. E135-E138, 2010.

[2] Z. He, C. Zhong, X. Huang et al., "Simultaneous enhancement of open-circuit voltage, short-circuit current density, and fill factor in polymer solar cells," Advanced Materials, vol. 23, no. 40, pp. 4636-4643, 2011.

[3] T. Y. Chu, J. Lu, S. Beaupré et al., "Bulk heterojunction solar cells using thieno[3,4-c]pyrrole-4,6-dione and dithieno[3,2- b:2',3' d] silole copolymer with a power conversion efficiency of 7.3\%," Journal of the American Chemical Society, vol. 133, no. 12, pp. 4250-4253, 2011.

[4] H. J. Son, W. Wang, T. Xu et al., "Synthesis of fluorinated polythienothiophene-co-benzodithiophenes and effect of fluorination on the photovoltaic properties," Journal of the American Chemical Society, vol. 133, no. 6, pp. 1885-1894, 2011.

[5] C. Piliego, T. W. Holcombe, J. D. Douglas, C. H. Woo, P. M. Beaujuge, and J. M. J. Fréchet, "Synthetic control of structural order in $\mathrm{N}$-alkylthieno[3,4-c]pyrrole-4,6-dionebased polymers for efficient solar cells," Journal of the American Chemical Society, vol. 132, no. 22, pp. 7595-7597, 2010.

[6] G. J. Zhao, Y. J. He, and Y. Li, " $6.5 \%$ efficiency of polymer solar cells based on poly(3-hexylthiophene) and indene-C60 bisadduct by device optimization," Advanced Materials, vol. 22, no. 39, pp. 4355-4358, 2010.

[7] P. Schlinsky, C. Waldauf, and C. J. Brabec, "Recombination and loss analysis in polythiophene based bulk heterojunction photodetectors," Applied Physics Letters, vol. 81, no. 20, p. 3885, 2002.

[8] H. Hoppe and N. S. Sariciftci, "Organic solar cells: an overview," Journal of Materials Research, vol. 19, no. 7, pp. 1924-1945, 2004.

[9] S. Gunes, H. Neugebauer, and N. Serdar Sariciftci, "Conjugated polymer-based organic solar cells," Chemical Reviews, vol. 107, pp. 1324-1338, 2007.

[10] T. Ameri, G. Dennler, C. Lungenschmied, and C. J. Brabec, "Organic tandem solar cells: a review," Energy and Environmental Science, vol. 2, no. 4, pp. 347-363, 2009.
[11] A. Yakimov and S. R. Forrest, "High photovoltage multipleheterojunction organic solar cells incorporating interfacial metallic nanoclusters," Applied Physics Letters, vol. 80, no. 9, p. 1667, 2002.

[12] M. Hiramoto, M. Suezaki, and M. Yokoyama, "Effect of thin gold interstitial-layer on the photovoltaic properties of tandem organic solar cell," Chemistry Letters, vol. 19, pp. 327-330, 1990.

[13] D. W. Zhao, X. W. Sun, C. Y. Jiang, A. K. K. Kyaw, G. Q. Lo, and D. L. Kwong, "Efficient tandem organic solar cells with an $\mathrm{Al} / \mathrm{MoO}_{3}$ intermediate layer," Applied Physics Letters, vol. 93, Article ID 083305, 2009.

[14] J. Sakai, K. Kawano, T. Yamanari et al., "Efficient organic photovoltaic tandem cells with novel transparent conductive oxide interlayer and poly (3-hexylthiophene): fullerene active layers," Solar Energy Materials and Solar Cells, vol. 94, no. 2, pp. 376-380, 2010.

[15] J. Y. Kim, K. Lee, N. E. Coates et al., "Efficient tandem polymer solar cells fabricated by all-solution processing," Science, vol. 317, no. 5835, pp. 222-225, 2007.

[16] J. Gilot, M. M. Wienk, and R. A. J. Janssen, "Double and triple junction polymer solar cells processed from solution," Applied Physics Letters, vol. 90, no. 14, Article ID 143512, 2007.

[17] S. Sista, M. H. Park, Z. Hong et al., "Highly efficient tandem polymer photovoltaic cells," Advanced Materials, vol. 22, no. 3, pp. 380-383, 2010.

[18] W. Chung, H. Lee, W. Lee et al., "Solution processed polymer tandem cell utilizing organic layer coated nano-crystalline $\mathrm{TiO}_{2}$ as interlayer," Organic Electronics, vol. 11, pp. 521-528, 2010.

[19] F. Verbakel, S. C. J. Meskers, and R. A. J. Janssen, "Electronic memory effects in diodes from a zinc oxide nanoparticlepolystyrene hybrid material," Applied Physics Letters, vol. 89, no. 10, Article ID 102103, 2006.

[20] A. K. Pandey, J. M. Nunzi, H. Wang et al., "Reverse biased annealing: effective post treatment tool for polymer/nanocomposite solar cells," Organic Electronics, vol. 8, no. 4, pp. 396400, 2007.

[21] A. Zaleska, "Doped- $\mathrm{TiO}_{2}$ : a review," Recent Patents on Engineering, vol. 2, no. 3, pp. 157-164, 2008.

[22] M. K. Seery, R. George, P. Floris, and S. C. Pillai, "Silver doped titanium dioxide nanomaterials for enhanced visible light photocatalysis," Journal of Photochemistry and Photobiology A, vol. 189, no. 2-3, pp. 258-263, 2007.

[23] F. Liu and J. M. Nunzi, "Air stable hybrid inverted tandem solar cell design," Applied Physics Letters, vol. 99, no. 6, Article ID 063301, 2011.

[24] P. V. Kamat, I. Bedja, and S. Hotchandanit, "Photoinduced charge transfer between carbon and semiconductor clusters. One-electron reduction of $\mathrm{C} 60$ in colloidal $\mathrm{TiO}_{2}$ semiconductor suspensions," The Journal of Physical Chemistry, vol. 98, pp. 9137-9142, 1994

[25] A. Zaban, S. Ferrere, J. Sprague, and B. A. Gregg, "pHdependent redox potential induced in a sensitizing dye by adsorption onto $\mathrm{TiO}_{2}$," Journal of Physical Chemistry B, vol. 101, no. 1, pp. 55-57, 1997.

[26] B. E. Yoldas, "Hydrolysis of titanium alkoxide and effects of hydrolytic polycondensation parameters," Journal of Materials Science, vol. 21, no. 3, pp. 1087-1092, 1986.

[27] Z. Zhang, C. C. Wang, R. Zakaria, and J. Y. Ying, "Role of particle size in nanocrystalline TiOi-based photocatalysts," Journal of Physical Chemistry B, vol. 102, no. 52, pp. 10871-10878, 1998. 
[28] H. Sakai, H. Kawahara, M. Shimazaki, and M. Abe, "Preparation of ultrafine titanium dioxide particles using hydrolysis and condensation reactions in the inner aqueous phase of reversed micelles: effect of alcohol addition," Langmuir, vol. 14, no. 8, pp. 2208-2211, 1998.

[29] J. Y. Kim, S. H. Kim, H. H. Lee et al., "New architecture for high-efficiency polymer photovoltaic cells using solution-based titanium oxide as an optical spacer," Advanced Materials, vol. 18, no. 5, pp. 572-576, 2006.

[30] Y. Yuan, J. Huang, and G. Li, "Intermediate layers in tandem organic solar cells," Green, vol. 1, pp. 65-80, 2011. 

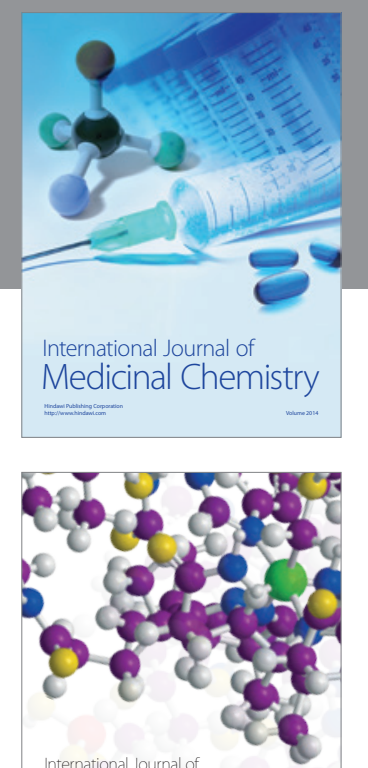

\section{Carbohydrate} Chemistry

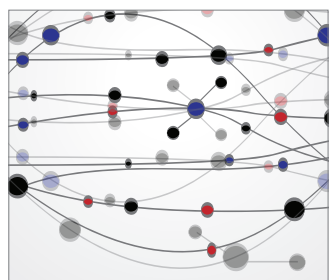

The Scientific World Journal
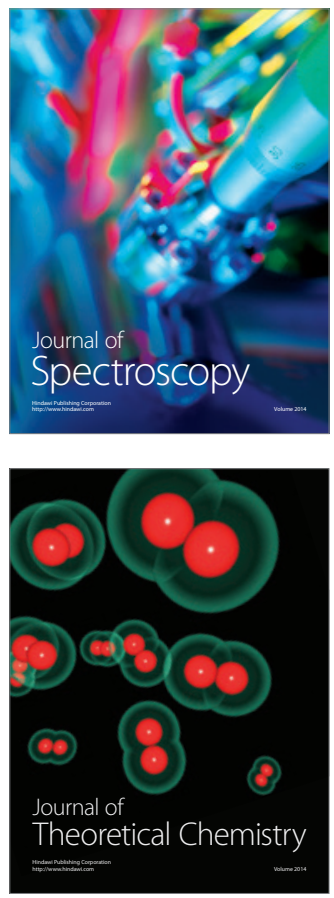
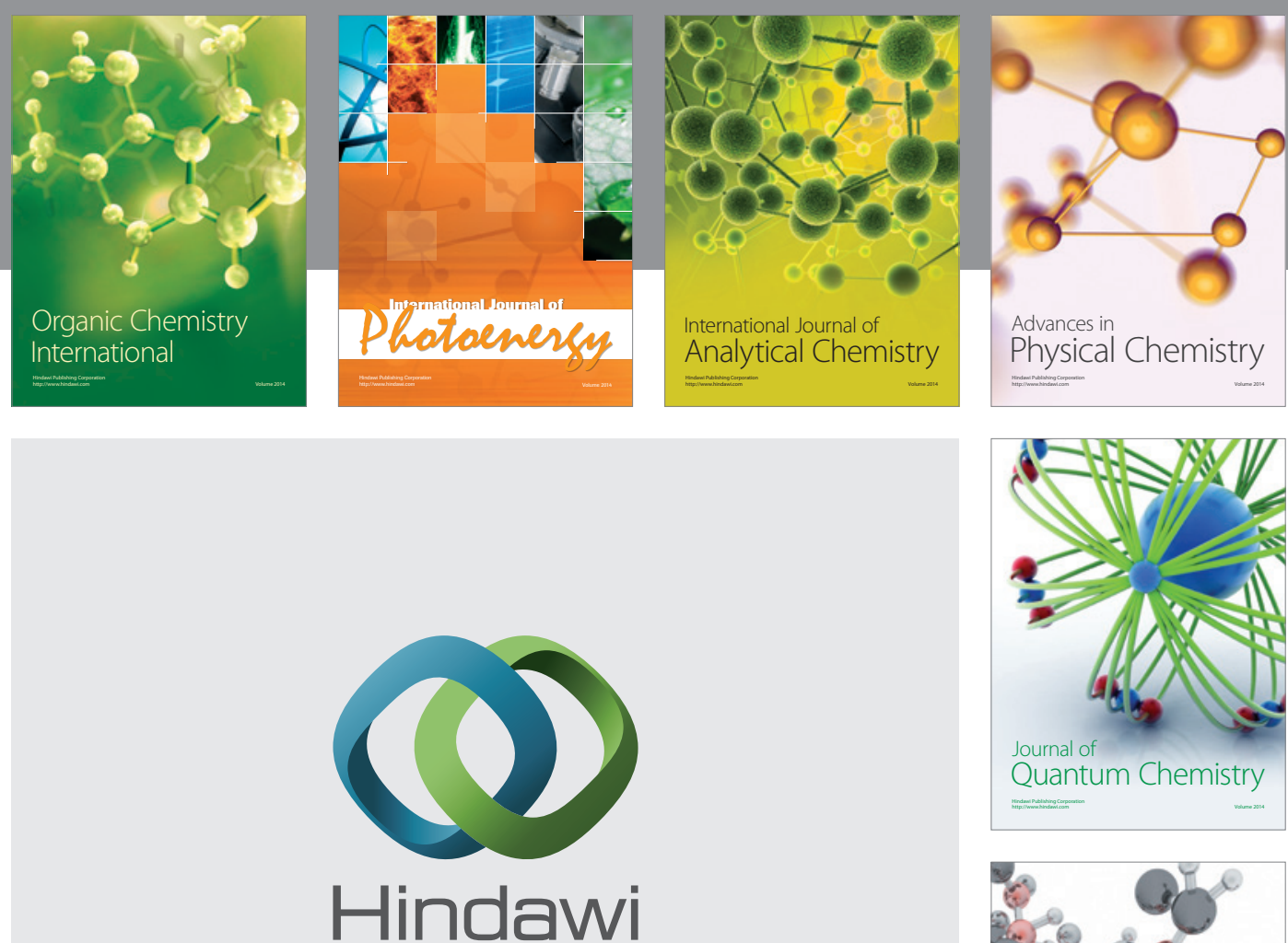

Submit your manuscripts at

http://www.hindawi.com

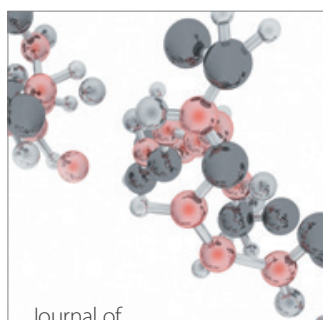

Analytical Methods

in Chemistry

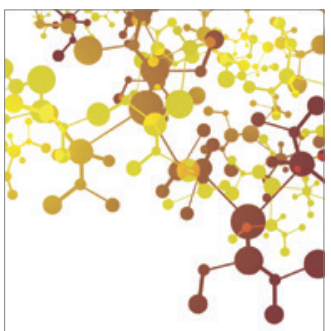

Journal of

Applied Chemistry

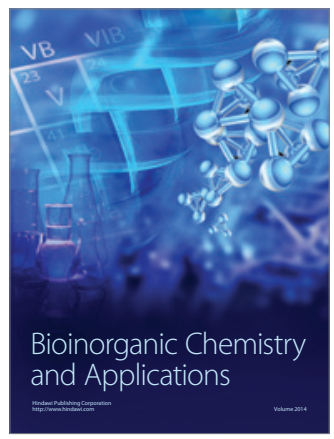

Inorganic Chemistry
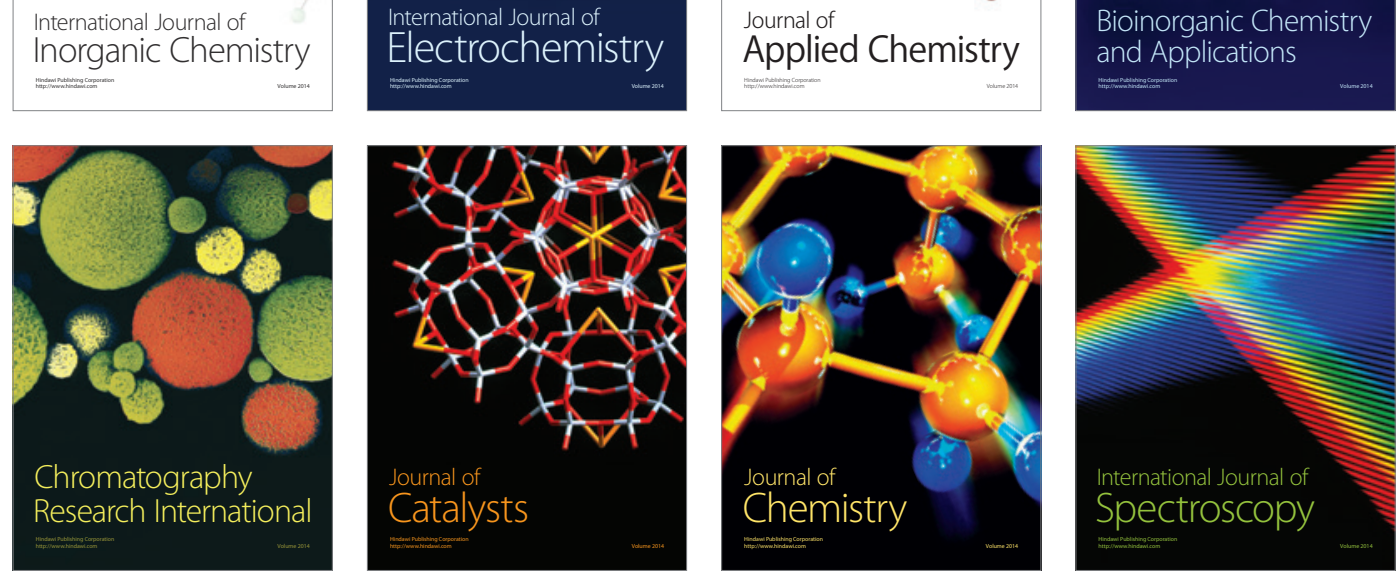